\title{
Determinants of active ageing in Zambia
}

\author{
Christopher Chabila Mapoma \\ University of Zambia, Humanities and Social Sciences \\ Department of Population Studies \\ P.O. Box 32379, Lusaka, Zambia. \\ Email:cmapoma@zambia.co.zm; Christopher.mapoma@unza.zm
}

\begin{abstract}
This study assesses the 2002 world health organisation Active Ageing Framework and how it applies to developing countries using data from Zambia. Up to date, there is little or no evidence of studies conducted to answer whether or not the 2002 world health organisation Active Ageing Framework is applicable to developing countries like Zambia. This study set out to (I) explore which of the determinants of the active ageing framework apply to Africa and Zambia in particular and, (2) the influence of HIV/AIDS on active ageing in general. A non-experimental exploratory research design was used to collect data for this paper. Snowball and purposive sampling was employed to select 690 respondents (284 males and 406 females) for the study. The study reveals that income accessibility (Economic Determinant), functional limitations (Health Determinants), low self-esteem and loneliness (Personal/Behavioural Determinants), low family and peer interactions (Social Determinants) and HIV/AIDS apply to Zambia in determining active ageing. The study suggests that focused research is needed to clarify and specify the role of each determinant, as well as the interactions between determinants in the active ageing process. In fact, the framework proposes that for such studies, a life course approach is required so as to take advantage of transitions and "window of opportunity" for enhancing health, participation and security at different stages. The study also recommends that policies on ageing should be structured to incorporate the applicability of the 2002 world health organisation active ageing framework's main determinants of active ageing to reflect the Zambian context.
\end{abstract}

Keywords: Zambia, Active-Aging, Applicability, Determinants

\section{Résumé}

Cette étude évalue le cadre pour le vieillissement actif de l'année 2002 de l'Organisation Mondiale de la Santé et comment il s'applique aux pays en voie de développement en considérant les données de la Zambie. Jusqu'à ce jour, il n'y a guère de preuve, voire aucune, des études menées pour répondre si le Cadre pour le Vieillissement Actif de l'année 2002 de l'organisation mondiale de la santé est applicable ou non aux pays en voie de développement comme la Zambie. Cette étude visait à (I) explorer lesquels des déterminants du cadre pour le vieillissement actif s'applique à l'Afrique et en particulier à la Zambie et, (2) l'influence du VIH / SIDA sur le vieillissement actif en général. Une méthodologie de la recherche exploratoire non-expérimentale $a$ été utilisée pour recueillir des données pour ce document. Cette étude s'est servie de l'échantillonnage en boule de neige et l'échantillonnage dirigé pour sélectionner les 690 répondants (284 hommes et 406 femmes). L'étude révèle que l'accessibilité au revenu (déterminants économiques), les limitations fonctionnelles (déterminants de la santé), faible estime de soi et la solitude (déterminants personnels / comportementaux), les interactions limitées au niveau familial et entre pairs (déterminants sociaux) et le VIH / SIDA s'appliquent à la Zambie pour déterminer le vieillissement actif. L'étude fait ressortir que la recherche ciblée est nécessaire pour clarifier et préciser le rôle de chaque déterminant, ainsi que les interactions entre les déterminants dans le processus de vieillissement actif. En fait, le cadre propose qu'une approche des parcours de vie est nécessaire pour de telles études afin de profiter de transitions et "la fenêtre d'opportunité» pour améliorer la santé, la participation et la sécurité à diverses étapes. L'étude recommande également que les politiques sur le vieillissement soient structurés de manière à intégrer l'applicabilité des principaux déterminants du cadre pour le vieillissement actif de l'année 2002 de l'organisation mondiale de la santé du vieillissement actif afin de refléter le contexte Zambien.

Mots-clés: Zambie, Vieillissement Actif, Applicabilité, Déterminants 


\section{Introduction}

The World Health Organization (2002) conceptualized "Active Ageing" as “...the process of optimizing opportunities for health, participation, and security in order to enhance quality of life as people age...". The idea, dating as far back as 1990, was a concerted effort between $\mathrm{WHO}$ and several other government and non-governmental organizations to help explain linkages between activity, health, independence, and ageing well (Constana et al, 20I2). Since this inception, several articles and papers have been written to highlight contextual as well as practical aspects of active ageing. In this process, it has been highlighted that scientific interests on the empirical dimension of active ageing have been scarce on the international level (Borsch-Span, 20I3). This assumption is even more critical to Africa where ageing is still being perceived as a "farfetched dream" and a problem of concern to western countries. However, notwithstanding this downplay of ageing in Africa, there clearly exists evidence to the contrary.

For example, Kalasa (2005) states that although Africa will remain relatively young for some time, old age dependency burden will increase by about 93 per cent by 2050 . In the same way, while the ratio of the population aged 60 years and above to the population aged $0-14$ years was 0.169 in 1950 and 0.212 in 1995 (a change of 25 per cent), the ratio will be 0.914 in the year 2050 (a change of 44I per cent from 1950 and 331 per cent from 1995). In essence, therefore, the 'window of hope' may not be as permanent as most people would like to think, and this signals the need for African countries to critically focus on elderly populations (Kidd, $\mathrm{S}$ et al 2009) and active ageing becomes an important input to this process. The concept of "active ageing" has not been measured to assume its importance and contribution to overall ageing in most parts of Africa (Leive, $A$ et al 2008). Moreover, there is little evidence to indicate whether or not research has surfaced to confidently apply "active ageing" with a focus on Africa and whether or not proposed determinants of active ageing could be applicable to most parts of Africa. In the same way, Africa is currently facing a huge challenge in the form of HIV/AIDS which consequently is affecting older people. The question therefore is: how applicable is the 2002 world health organisation Active Ageing Framework to developing countries such as Zambia? And to what extent is HIV/AIDS a determinant of Active Ageing in Zambia? Rephrasing what Constana (20I2) proposed, this paper seeks to apply the 2002 world health organisation active ageing framework to developing countries: a case study of Zambia. This paper sets out to $(I)$ assess how applicable the 2002 world health organisation active ageing framework is to developing countries and Zambia in particular and (2) determine how HIV/AIDS affects active ageing in Zambia in general.

\section{Data and Methods}

We conducted a cross-sectional population-based survey of participants aged 60 years and older within the four homes for the aged Matero, Kandiana, Maramba, Mitanda and Chibolya located in Lusaka, Sesheke, Livinstone, Ndola and Mufulira districts, respectively. The sample comprises a rural and urban dimension, men and women in $4 \mathrm{I} .2$ per cent and $\mathbf{5 8 . 8}$ per cent proportions. Kandiana is predominately in a peri-urban rural setting of western province bordering Namibia whereas Matero, Mitanda and Chibolya are within the heart of the urban settings. Respondents were drawn from homes for the aged, inclusion-exclusion criteria were based on the ability to communicate and converse and as such the very sick where excluded for interviews.

\section{Data Collection}

Interviewer administered questionnaires were used to collect demographic data on individual, socioeconomic, HIV and AIDS, behavioural and health/functional indicators of active ageing. Men and women aged 60 years and older institutionalized (those found in old people's homes) as well as uninstitutionalized aged people living in study areas were surveyed.

Standardized procedures of purposive and snowball sampling were employed in identifying respondents for the study. Purposively, all residents in existing old people's homes were targeted for the study. In addition, samples of the aged living in communities were selected through snowball sampling (Goodman, L.A. 196I; Salganik, M.J. and D.D. Heckathorn, 2004). The approach was useful as the study population has no known sampling frame as well as the sensitivity associated with aging in Zambia such as witchcraft. Lusaka had the highest number of respondents (296), followed by Ndola (195), Sesheke (125), Mufulira (50) and Livingstone (24). In total, a sample of 690 men and women aged 60 years and older was archived.

\section{Definition of old people "aged"}

In the early 1970s, the Zambian government defined aged persons as generally any woman above age 40 
or any man over 50 years (Zambia's Report for the 1982 World Assembly on Ageing). However after setting the statutory age for retirement at age 55 for females and 60 years for males and with similar requirements for admission to the Homes for the aged, a new concept to determine old age was created (Kamwengo 2004). Unfortunately, even up to now, there is no clear guide as to who qualifies to be classified as "an old person". Retirement age in Zambia is 55 years for both males and females; the discriminatory clause where females were required to retire earlier than males was eliminated from the statutory instruments.

The actual chronological age attainment for one to qualify to be "old" still remains a debatable concept and varies with region and context. For example, the United Nations defines an old person as one who is 60 years and older; the Zambia's health policy on the other hand states that for one to have free access to medical services, one has to be at least 65 years or older. Thus, the synchronization and the meaning of chronological age attained to be classified as aged still lacks a universally acceptable threshold. In this paper however, the UN definition is followed.

\section{Model for Determinants of Active Ageing}

Determinants of the WHO active ageing framework were measured using proxy indicators including Gender and residence. Residence was measured by either urban or rural areas (in Zambia, the plight of the aged and active ageing differences are reflected easily by one's residence) while gender was reflected or measured through one's sex.

Behavioural and Personal Determinants were measured using indicators such as feeling, hopeless, useless, unhappy or lonely, dignity and self image among others.

Health and Functional Determinants were measured using the following indicators (say either "yes" or "no"): able to squat, ability to walk freely, and ability to clean own house.
Economic Determinants were measured using indicators such as: having worked in the past 12 months, having opportunities for work, and having a steady flow of income.

Indicators on Social Determinants included information on caretakers, living arrangements, peer and family interactions, and receipt of any support.

Finally, HIV/AIDS, unique to Zambia and Southern Africa in general, but not reflected in the Active Ageing Framework (WHO, 2002), was measured using indicators such as: staying with dependents; staying with orphans; whether these were HIV/AIDS orphans; and whether they had lost children due to AIDS to see if it had any effect on the active ageing. These indicators were used to reflect the effect of HIV and AIDS on active aging "reports HIV/AIDS".

In the Active Ageing Framework, the above determinants were or are treated as "Independent variables" while Active ageing (measured by participation, self fulfillment, independence and dignity) was measured as the "Dependent variable". Table 2 shows descriptive statistics of determinants of active ageing and indicators of active ageing.

\section{Results}

A total of 700 participants were surveyed; 10 were excluded from the analysis due to incomplete data (age, sex data), leaving 690 (284 males and $406 \mathrm{fe}$ males) representing 98 per cent response rate. The socio-demographic characteristics of the study population are shown in table I. The sample contained more females than males; the mean age for the population was about 72 years, with more respondents from the urban settings than rural areas. Majority of respondents were widowed with females exhibiting a higher percentage compared to males. Similarly, more males than females reported being married. In fact, this is a reflection of the norm in most African societies. Overall, also primary education attainment is more prominent (52 per cent) compared to higher education (15.8per cent) and those reporting never having attended school (32 per cent) respectively. 
Table I: Description of sample of elderly Zambians (60 years and above)

\begin{tabular}{l|lll}
\hline \multicolumn{1}{l}{ Total population } & Males & Females \\
\hline N & 690 & 284 & 406 \\
Mean Age & 72.1 & 73.7 & 71 \\
\hline \% Residence & & & \\
Urban & 81.7 & 86.2 & 13.8 \\
Rural & 18.3 & 78.5 & 21.5 \\
\hline \% Marital status & & & \\
Never & 3.77 & 4.23 & 3.45 \\
Married & 35.8 & 56.34 & 21.43 \\
Divorced/Separated & 11.45 & 13.03 & 10.34 \\
Widowed & 48.99 & 26.41 & 64.78 \\
\hline \% Education & & & \\
Never & 32.17 & 18.66 & 41.63 \\
Primary & 52.03 & 55.63 & 49.51 \\
Higher & 15.8 & 25.7 & 8.87 \\
\hline
\end{tabular}

According to the Active Ageing Framework, active ageing depends on a variety of influences or "determinants" that surround individuals, families and the nations (WHO 2002). These determinants are varied and are known to affect active ageing differently. Among the varied factors are; gender and residence, economic, health, social, physical environment and psychological or behavioural which play a central role in the active aging framework. This study also endeavored to situate the influence of HIV and AIDS in the active aging framework, particularly the lives of older people in Zambia, and much of Africa as a whole. HIV/AIDS was included because of its influence on the lives of older people particularly older people who are left to look after orphaned children as a result of HIV. This situation in most cases exacerbates the poverty levels of already impoverished old people headed households. Thus in order to appropriately assess the applicability of the model to Zambia, HIV is an indispensable factor. We excluded the "physical environment" determinant because the context in which it is used in developed countries is very different from what could be referred to as physical environment in an African setting. For example, the determinant in question proposes that for people to age actively, there is a need to build structures which take into account their physical limitations i.e. all buildings should have "escalators" and not just stairs. Figure I.I and I.2 are the original and modified 2002 WHO Active Ageing Frameworks, respectively. 
Figure I.I Original WHO Active Ageing Framework

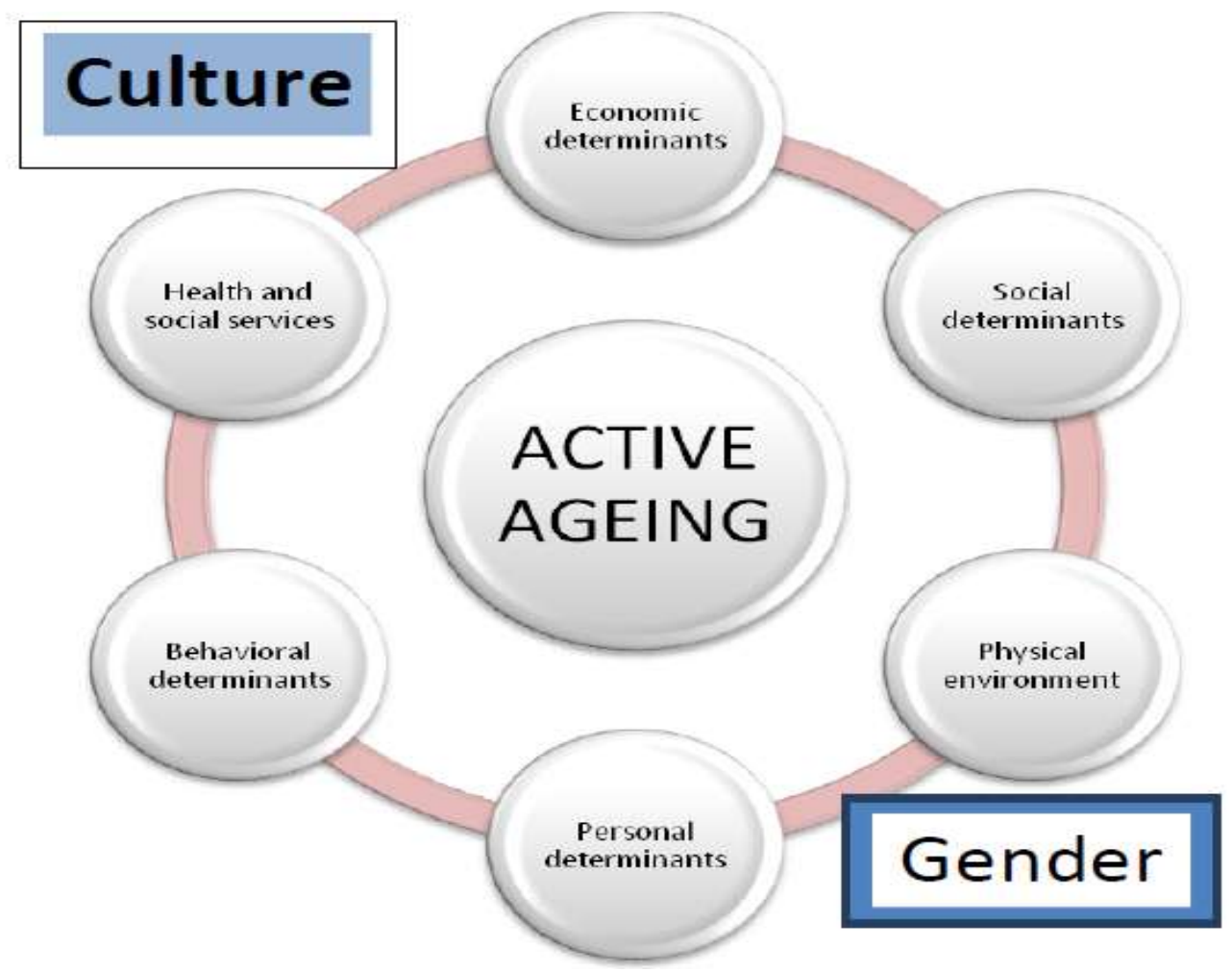

Figure I.2 Modified WHO Active Ageing Framework with HIV/AIDS

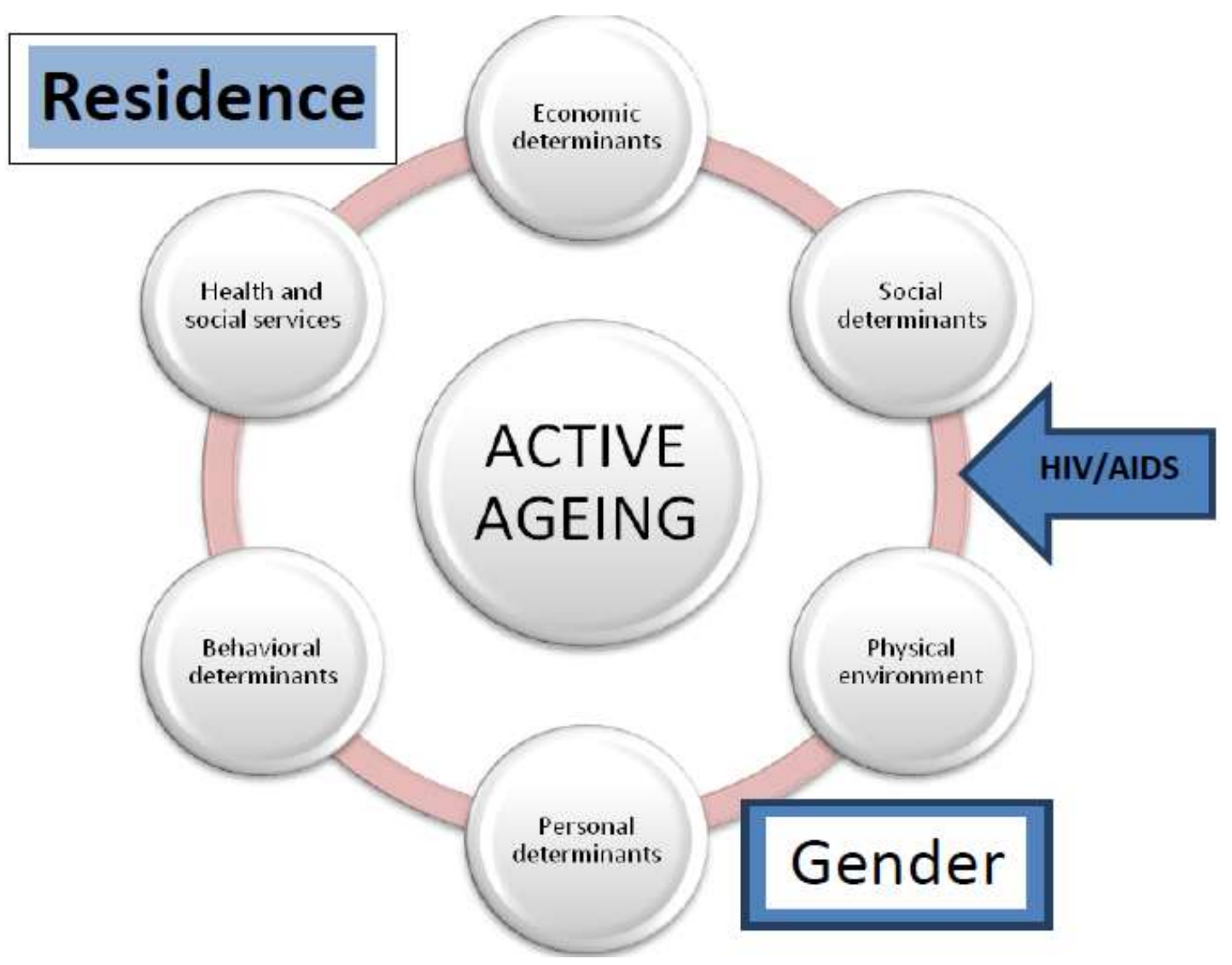


It should also be borne in mind that Active Ageing is not a concept measurable using a single variable - it is complex. Using the definition of the concept itself, active ageing should include: independence, participation, self-fulfillment, dignity and care. Out of these, four variables-independence, participation, self-fulfillment and dignity were captured in the data collection process. Independence for example was measured by asking the respondent to state

whether they were free to make their own decisions without being coerced or forced; participation was also measured by asking respondents to state whether they were free and allowed to participate in community activities such as church gatherings, community meetings etc. Any "yes" response to these questions meant that they were participating in community activities and therefore fulfilling partly the active ageing process.

Table 2 Percent distribution of Determinants of Active Ageing and Selected Indicators of Active Ageing

\begin{tabular}{|c|c|c|c|c|c|}
\hline \multirow{3}{*}{$\begin{array}{l}\text { Determinants } \\
\text { of Active Ageing }\end{array}$} & \multirow[b]{3}{*}{$\mathbf{N}$} & \multicolumn{4}{|c|}{ Selected Indicators of Active ageing } \\
\hline & & & Self & & \\
\hline & & Participation & Fulfillment & Independence & Dignity \\
\hline \multicolumn{6}{|l|}{ Sex } \\
\hline Male & 286 & 88.8 & 16.1 & 79.7 & 72.6 \\
\hline Female & 409 & 91.9 & 5.3 & 72.1 & 67.5 \\
\hline \multicolumn{6}{|l|}{ Residence } \\
\hline Urban & 566 & 92.1 & 10.2 & 76.8 & 70.6 \\
\hline Rural & 129 & 84.5 & 7.7 & 68.2 & 69.2 \\
\hline \multicolumn{6}{|c|}{ Personal/Behavioural } \\
\hline "Feels" Hopeless & 210 & 87.6 & 10.0 & 63.8 & 68.4 \\
\hline Useless & 191 & 83.8 & 12.5 & 60.2 & 70.7 \\
\hline Unhappy & 311 & 87.5 & 10.9 & 68.2 & 75 \\
\hline Lonely & 364 & 86.8 & 11.5 & 70.8 & 73.3 \\
\hline \multicolumn{6}{|l|}{ Health/Functional } \\
\hline III past I 2 months & 433 & 88.6 & 10.3 & 71.5 & 76.2 \\
\hline Can squat & 487 & 93.0 & 8.8 & 85.2 & 83.1 \\
\hline Walk freely & 522 & 91.9 & 9.3 & 81.6 & 79.7 \\
\hline Clean house & 499 & 93.4 & 8.8 & 81.9 & 77.9 \\
\hline \multicolumn{6}{|l|}{ Economic } \\
\hline Work past 12 months & 86 & 91.8 & 2.3 & 86.1 & 71.4 \\
\hline Opp/work/income gen & 176 & 93.7 & 5.6 & 87.5 & 76.4 \\
\hline Monthly income & 158 & 96.2 & 2.5 & 91.7 & 60 \\
\hline \multicolumn{6}{|l|}{ Social } \\
\hline Has caretaker & 417 & 87.2 & 12.4 & 66.9 & 78.5 \\
\hline Living with anyone & 523 & 90.2 & 0.2 & 77.4 & 50 \\
\hline Interact with peers & 480 & 93.5 & 100.0 & 80.6 & 50 \\
\hline Receives support & 176 & 85.8 & 100.0 & 64.2 & 52.1 \\
\hline \multicolumn{6}{|l|}{ HIV/AIDS } \\
\hline Reports HIV & 293 & 93.8 & 0.0 & 83.9 & 50 \\
\hline
\end{tabular}

Table 2 shows that for almost all indicators of active ageing, the primary determinants seem to have influences. In this case for example, the respondent's sex influences how older people participate (88.8 and 91.2 per cent for males and females, respectively) in communities; it also influences how independent (79.7 and 72.I per cent for males and females, respectively) they are as well as whether they live dignified lives or not (72.6 and 67.5 per cent for males and females, respectively). Similarly, for almost all determinants of active ageing, self-fulfillment seems to be the least affected amongst indicators of active ageing. Except for "receiving support" (100 per cent), and "interacting with peers" (100 per cent), other influences are all under 16.1 per cent reported by the male participants.

Except for participation where the females seem to be more (9l.9 per cent), males seem to be more self-fulfilled (16.I per cent), more independent (79.7 per cent) and more dignified (72.6 per cent).

The rural-urban residence of old people brings to perspective differentials in the concept of active ageing. Residents in urban areas appear to participate more in community activities (92.I against 84.5 
per cent), are likely to be more self-fulfilled (10.2 against 7.7 per cent) and more independent (76.8 against 68.2 per cent) compared to their rural counterparts, respectively. However, in terms of dignity, older people in both rural and urban areas seem to enjoy relatively similar treatment (70.6 and 69.2 per cent respectively).

While it is clear that other determinants play quite an important role in explaining active ageing and the data suggesting relatively high influence on active ageing process, there are few or exceptional variations amongst and between them.

The behavioural and personal determinants indicate that at least four out of every five respondents demonstrate that these determinants affect the way they participate. Being unhappy and reporting loneliness for example is associated with the respondent's independence (68.2 and 70.8 per cent respectively) and dignity (75 and 73.3 per cent respectively).

Health Determinants also show indications of associations with active ageing indicators relating especially to participation in community activities, independence and dignity. About 88.6 percent of respondents stated that while they were ill in the past 12 months prior to the study, they however reported that they were free to participate in the affairs of society.
Economic determinants, especially having a monthly income (from any source), are associated with active ageing indicators of participation (96.2 per cent) and independence ( 91.7 per cent). Similarly, social determinants appear to have an effect on active ageing indicators differently. However, this association is more visible with participation in community activities and independence than with other indicators.

The influence of HIV and AIDS in the active ageing process cannot be ignored particularly in the sub-Saharan region. HIV and AIDS appear to affect participation activities (93.8 per cent) more than any of the other determinants. However, HIV and AIDS appear to have no clear influence on the active ageing indicator of self-fulfillment. In other words, being affected by HIV and AIDS or taking care of HIV and AIDS orphans do not suggest an influence on selffulfilled lives of participants.

\section{Determinants of Active Ageing}

In order to measure the influence of each of the determinants on indicators of active ageing, a regression analysis model was used. All outcome and Independent variables remained as they appear in descriptive table 2. Details of these relationships are in table 3. 
Table 3 Determinants of Active Ageing relative to Active Ageing indicators

\begin{tabular}{|c|c|c|c|c|c|}
\hline \multirow{3}{*}{$\begin{array}{l}\text { Determinants } \\
\text { of Active Ageing }\end{array}$} & \multirow[b]{3}{*}{$\mathbf{N}$} & \multicolumn{4}{|c|}{ Selected Indicators of Active ageing } \\
\hline & & \multirow[b]{2}{*}{ Participation } & \multicolumn{2}{|l|}{ Self } & \multirow[b]{2}{*}{ Dignity } \\
\hline & & & Fulfillment & Independence & \\
\hline Sex & 690 & -0.0312 & ****0.1070 & $* 0.0759$ & 0.0497 \\
\hline Residence & 690 & $* * 0.0755$ & 0.0250 & $* 0.0863$ & 0.0794 \\
\hline \multicolumn{6}{|l|}{ Personal/Behavioural } \\
\hline "Feels" Hopeless & 210 & *0.0762 & -0.0664 & -0.0101 & -0.1470 \\
\hline Useless & 191 & $*+-0.1305$ & $* 0.0793$ & $* *-0.1727$ & 0.0317 \\
\hline Unhappy & 311 & -0.0062 & -0.0030 & -0.075 I & 0.0481 \\
\hline Lonely & 364 & $*-0.0601$ & 0.0340 & 0.0048 & -0.0566 \\
\hline \multicolumn{6}{|l|}{ Health/Functional } \\
\hline III past I 2 months & 433 & -0.0204 & 0.0077 & 0.0086 & 0.0382 \\
\hline Can squat & 487 & 0.0392 & -0.0326 & $* * * 0.2559$ & 0.1806 \\
\hline Walk freely & 522 & -0.0274 & 0.0161 & 0.0486 & 0.0384 \\
\hline Clean house & 499 & $* * * 0.1163$ & -0.0098 & $*+0.1246$ & 0.0043 \\
\hline \multicolumn{6}{|l|}{ Economic } \\
\hline Work past 12 months & 86 & -0.0186 & -0.0530 & 0.0237 & -0.0265 \\
\hline Opp/work/income gen & 176 & 0.0172 & -0.0082 & $* 0.0860$ & 0.0974 \\
\hline Monthly income & 158 & $* 0.0681$ & $* *_{-}-0.078 \mathrm{I}$ & $* * * 0.1690$ & -0.2300 \\
\hline \multicolumn{6}{|l|}{ Social } \\
\hline Has caretaker & 417 & $* * *-0.0938$ & ,- & ****-0.208I & ,- \\
\hline Living with anyone & 523 & 0.0358 & ,- & $* * 0.1600$ & ,- \\
\hline Interact with peers & 480 & $* * * 0.1499$ & ,- & $* * * 0.1732$ & ,- \\
\hline Receives support & 176 & -0.0325 & ,- & $* *-0.1113$ & ,- \\
\hline \multicolumn{6}{|l|}{ HIV/AIDS } \\
\hline Reports HIV & 293 & $* * 0.0690$ & -0.0033 & $* * * 0.1405$ & ,- \\
\hline$* * * P<0.0001$ & $* P<0.05$ & $* * P<0.01$ & $*+P<0.001$ & & \\
\hline Opp/work/income gen & \multicolumn{5}{|c|}{$=$ opportunity for work or income generating activity } \\
\hline
\end{tabular}

Associations in the table show that gender influences active ageing indicators of independence $(p<0.05)$ and self-fulfillment $(p<0.000 \mathrm{I})$. However, there is no statistical association between one's sex and active ageing indicators of participation in activities and dignity. On the other hand, residence has no bearing on older people's dignity and self fulfillment, but is statistically associated with both participation $(p<0.0 \mathrm{I})$ and independence $(\mathrm{p}<0.05)$.

Personal/Behavioural determinants of active ageing are associated to active ageing indicators of participation, self fulfillment and independence. In this example, almost all measures of personal/behavioural determinants are associated with the active ageing indicator of participation (hopeless $(p<0.05)$; useless $(p<0.00 \mathrm{I})$; lonely $(p<0.05))$ except for that of "being unhappy". In other words, there is no significant association between being unhappy and being able to participate in community or society's activities. Similarly, the relationship between the personal/behavioural determinant indicator of "feeling useless" is significant with both the active ageing indicators of self-fulfillment $(p<0.05)$ and independence $(p<0.0 \mathrm{I})$. Given these results, it is clear that the main problem in as far as older peo- ple are concerned is low self-esteem. Low selfesteem inhibits old people's full participation in several activities taking place at either community or society level.

The active ageing framework proposes that health and functional abilities have substantial effects on ageing in general. Results in table 3 show that there is no significant association between the respondent's report of being "ill in the last 12 months prior to the study" and any other indicator of active ageing. This finding is at variance with the propositions in the active ageing framework, where health is a key determinant. However, this may mean that illness may only affect active ageing if and when it is experienced over a long period of time. Ability to "clean the house" is related to the active ageing indicator of "participation" $(p<0.000 \mathrm{l})$ and independence $(p<0.00 \mathrm{I})$; while "being able to squat" is only significant with the active ageing indicator of "independence" $(p<0.000 \mathrm{I})$. This shows that, while health indeed affects the ageing process, this relationship can best be measured by a life course approach and is more factual when it relates to actual physical activity where older people have to perform 
more physical abilities, rather than reports of being ill for example. While it could be argued that health is a significant challenge in old age, the effect it has on the actual active ageing process is minimal except where one has lifelong health challenges.

Economic determinants are also said to have a bearing on the active ageing process. However, the economic determinant indicator measured by proxy of whether or not someone "worked in the last 12 months prior to the study" is not statistically significant on active ageing indicators. The work in this respect refers to any work done by the elderly and is paid for irrespective of the duration of the work done. The economic determinant indicator of "having opportunities for work or income generating activities" has no bearing on almost all active ageing indicators except that of independence $(p<0.05)$. The main economic determinant indicator influencing participation, self-fulfillment and independence is "monthly income", Monthly income refers to income/money received either from work done, retirement or any other source. In fact, respondents' report of having a steady "monthly income" affects their participation $(p<0.05)$, self-fulfillment $(p<0.0 \mathrm{I})$ and also their independence $(p<0.000 \mathrm{I})$. While the relationship between income and active ageing indicators of participation and independence is positive, the relationship between income and self-fulfillment is actually negative (coef $=-0.078 \mathrm{I}$ ) meaning therefore old people with no monthly income have low self-fulfillment in this context.

An association between social indicators of determinants of active ageing and active ageing indicators is also shown in table 3. Self-fulfillment and dignity are not statistically associated with the social determinants proposed in the active ageing framework. However, all, except for two of the measured indicators of social determinants of active ageing (living with anyone and receiving support) seem to affect active ageing indicators of participation and independence. Participation is affected by whether or not a respondent has a caretaker $(p<0.000 \mathrm{l})$ and whether or not a respondent interacts with peers $(p<0.000 \mathrm{I})$; these relationships are quite strong. In the same way, the active ageing indicator of independence is related to all social determinants of active ageing with "having a caretaker" $(p<0.0 \mathrm{I})$, and "receiving support" $(\mathrm{p}<0.000 \mathrm{I})$ having a negative relationship.

Lastly, our study looked also at the effect HIV/AIDS is having on active ageing. This situation is not proposed through the active ageing framework but thought to have effects on active ageing as this is a common phenomenon in Sub Saharan Africa and Zambia in particular. Table 3 shows that HIV/AIDS is related to the active ageing indicator of participation $(p<0.0 \mathrm{I})$ and independence $(p<0.000 \mathrm{I})$. However, HIV/AIDS has no bearing on one's self-fulfillment and dignity. This means that old people's report of HIV/AIDS affects how they participate in community activities as well as their independence. What this shows is that older people, who could be keeping orphans for example, are not as independent to be able to do what they want and whenever they want because they have to take care and look after orphans. This is a serious and daunting challenge affecting older people in Zambia and other African countries where the HIV/AIDS pandemic is highly pronounced and generalized.

In summary, table 3 suggests that active ageing is a function of most of the determinants proposed in the active ageing framework or model. Even with the presence of HIV/AIDS, the relationship with indicators of determinants of active ageing and indicators of active ageing itself is quite strong.

Discussions above are not conclusive. As a result, for the study to accurately establish the applicability of the $\mathbf{2 0 0 2}$ world health organisation active ageing framework to Africa and Zambia in particular and also to establish "pathways" affecting active ageing significantly, we generated a composite variable compressing all indicators of active ageing into a variable called "Active Ageing".

The input variables for all or most of the indicators of active ageing were generated by "yes" and "no" responses. For example, for us to investigate whether any respondent was "participating" in community activities, we asked them to confirm (yes) or disapprove (no) whether they were given chances to participate in community activities such as going to church; being given positions of authority; being considered to head community groupings etc. Any "yes" response to such a statement meant that a respondent was participating while a negative outcome meant the opposite. This process was followed through for other indicators of active ageing self-fulfillment, independence and dignity. In order to finally come up with the outcome variable of "Active Ageing", all "yes" responses to the preceding conditions or questions meant a respondent was enjoying active ageing while "No" responses meant the opposite. This process provided a demonstration of determinants of active ageing and pathways with influences on active ageing relating to Zambia. Table 4 shows results of indicators (or pathways) of 
Table 4 Determinants of Active Ageing in Zambia

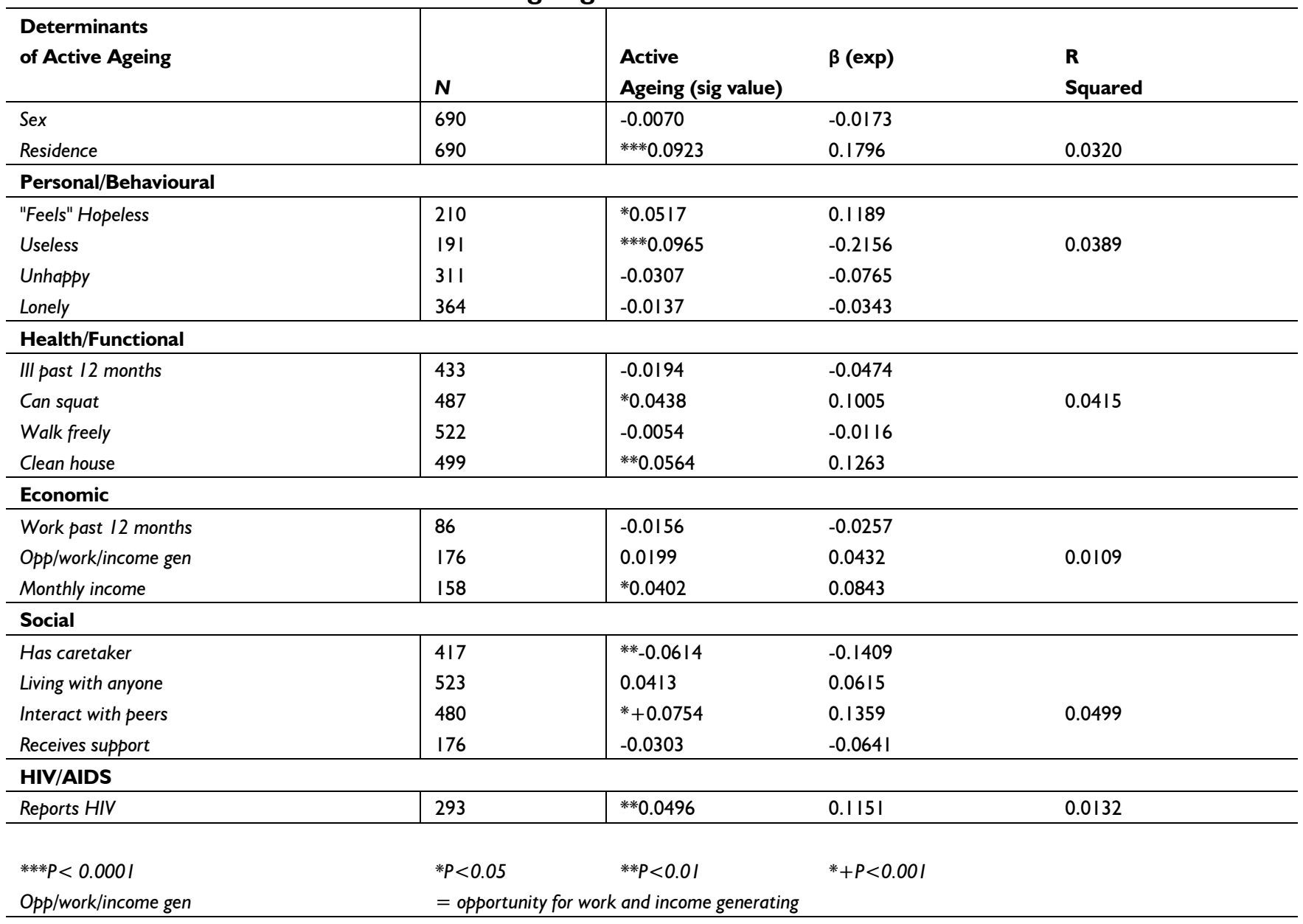

Table 4 shows that gender does not influence active ageing, even if it does influence some individual indicators of active ageing (table 3). This finding defies propositions given in the Active Ageing Framework where gender is an overarching variable influencing active ageing in general. Culture, however influences active ageing $(p<0.0001$; Beta $=179)$; confirming also what the active ageing framework proposes. It should also be noted that actually, even after controlling gender against culture and vice versa, the relationships between gender and active ageing on one side and culture and active ageing on the other, remained the same - gender does not influence active ageing while culture does. To some extent, this revelation marries well with the Active Ageing Framework assumption stating the uncertainty with which one can predict or point out direct causation of anyone determinant on active ageing (Active Ageing Framework pp. 19). It is also suggested that more research is needed to clarify and specify the role of each determinant, as well as the interactions between determinants in the active ageing process. In fact, the framework proposes that for such studies, a life course approach is required so as to take advantage of transitions and "window of opportunity" for enhancing health, participation and security at different stages (Active Ageing Framework 2002 pp. 19-20).

Results in table 4 also show that amongst person$\mathrm{al} /$ behavioural determinants of active ageing, only feelings of "hopelessness" $(p<0.05)$ and that of "uselessness" $(p<0.000 I)$ explain variations on the outcome variable of active ageing. Actually, this model predicts that feeling useless is negatively related to active ageing (Beta $=-2 \mid 5)$. Other indicators of personal/behavioural determinants of active ageing have no bearing on the process of ageing in general.

In the same way, health and some functional disabilities do not affect active ageing. However, ability to squat $(p<0.05)$ and clean the house $(p<0.01)$ affect older people substantially. In terms of economic determinants, the model suggests that only "having a steady monthly income" $(p<0.05)$ affects active ageing. Other economic determinants have no bearing on active ageing.

This model also suggests that the major social (determinants) contributors to active ageing are 
"having a caretaker" $(\mathrm{p}<0.0 \mathrm{I})$ and "interacting with peers" $(p<0.00 \mathrm{I})$. Others, such as "living with other adult children" and "receiving any form of support" do not affect active ageing. In the same way, HIV/AIDS, a special situation prominent in Africa and Zambia in particular, is associated with active ageing $(p<0.0 \mathrm{I})$. Even after controlling for other determinants, the relationship between HIV/AIDS and active ageing still remained significant.

\section{Discussion}

This study set out to assess how applicable the 2002 world health organisation active ageing framework is to developing countries and Zambia in particular and (2) determine how HIV/AIDS affects active ageing in Zambia in general. Using data derived from extensive investigation of determinants of active ageing, we employed both the bivariate and multivariate. It was revealed that in the Zambian context, the personal/behavioural factors were associated with active ageing particularly relating to "feeling hopeless and useless", health/functional factors are associated to the ability "to squat and cleaning one's house", whereas economic factors (access monthly income, paid word) were associated with active ageing, similarly, social factors relating to "having a caretaker and interacting with friends or peers" increases the probability of ageing actively. These results corroborate with the WHO framework on active ageing.

What is clearly different from the active ageing framework is that this study has situated HIV and AIDS within the active ageing framework and confirms that in the Zambian context and also in countries with a generalized HIV/AIDS pandemic, active ageing will be affected by HIV/AIDS for a long time. Suffice to say the influence of HIV and AIDS on active ageing is far-reaching, particularly that most of the old people not only suffer neglect, poverty, insecure housing in their old age, they are also left with the responsibility of taking care of orphaned children which in most cases exacerbates the already impoverished households. This shows that the 2002 world health organisation active ageing framework is applicable to Zambia but not to a very large extent as it overlooks the aspect of HIV/AIDS, which is very critical to developing countries and Zambia in particular.

\section{Conclusion}

The plight of the old people should be re-looked in order to ensure active aging and a favorable old age in Zambia. Government effort should be geared towards eliminating location or regional disparities (rural/urban) in active ageing. The health systems need to be re-aligned to prepare and accommodate the challenges of the aged as the health or functional challenges among the aged are often inevitable.

The study clearly has demonstrated the need to strengthen the weakening family ties and structure in an effort to curtail the social factors that have arisen mainly due to the modernization of the extended family system to a nuclear family system.

However, we believe that the influence of this factor is not categorical in the active ageing framework. In order to measure active ageing with utmost precision, long term studies which will show exactly how and at what point each of these determinants affect ageing should be encouraged. In fact, points of emphasis for the framework should incorporate differentials obtaining in different countries and that for policies to reflect active ageing in Zambia, they should have these main determinants which are applicable to the Zambian context.

\section{References}

World Health Organisation ( 2007). Active Ageing Framework (2002).

Axel Borsch-Span (20I3). Myths, Scientific evidence and economic policy in an ageing world. The Journal of Economics of Ageing, 2013

Constança Paúl, Oscar Ribeiro and Laetitia Teixeira (2012). Active Ageing: An Empirical Approach to the WHO Model. Current Gerontology and Research Volume 2012 (20I2), Article ID 382972, 10 pages

Kalasa, Benoît. (2005). Population and ageing in Africa: a Policy Dilemma? Support Team, Addis Ababa, Ethiopia

Kamwengo, Martin. (2004). Growing old in Zambia: Old and New Perspectives. Sterling International, New Delhi, India

Kidd, S. and E. Whitehouse (2009). Pensions and old age poverty: in R. Holzmann, D. Robalino, and N. Takayama (eds.), Closing the Gender Gap: The Role of Social Pensions. Washing-ton, DC: World Bank.

Leive, A. and K. Xu (2008). Coping with out-ofpocket health payments: empirical evidence from 15 African countries. Bulletin of the World Health Organization, 86(II) 